NBER WORKING PAPER SERIES

HOUSEHOLD BALANCE SHEET CHANNELS OF MONETARY POLICY: A BACK OF THE ENVELOPE CALCULATION FOR THE EURO AREA

\author{
Jiri Slacalek \\ Oreste Tristani \\ Giovanni L. Violante \\ Working Paper 26630 \\ http://www.nber.org/papers/w26630 \\ NATIONAL BUREAU OF ECONOMIC RESEARCH \\ 1050 Massachusetts Avenue \\ Cambridge, MA 02138 \\ January 2020
}

We thank Felipe Alves, Hugo Lhuillier, Adrian Monninger, Alessandro Pizzigolotto and Francisco Rodrigues for excellent research assistance. We also thank Fernando Alvarez, Rudi Bachmann, Florin Bilbiie, Chris Carroll, Gabriel Chodorow-Reich, Bill Dupor, Nicola FuchsSchündeln, Luigi Guiso, Jonathan Heathcote, Geoff Kenny, Luc Laeven, Michele Lenza, Davide Malacrino, Benjamin Moll, Dirk Niepelt, Ricardo Reis, Michael Reiter, and Christian Wolf for their comments. We are especially grateful to Ralph Luetticke for his insightful discussion. All opinions expressed are personal and do not necessarily represent the views of the European Central Bank or the European System of Central Banks. This paper uses data from the Eurosystem Household Finance and Consumption Survey. The views expressed herein are those of the authors and do not necessarily reflect the views of the National Bureau of Economic Research.

NBER working papers are circulated for discussion and comment purposes. They have not been peerreviewed or been subject to the review by the NBER Board of Directors that accompanies official NBER publications.

(C) 2020 by Jiri Slacalek, Oreste Tristani, and Giovanni L. Violante. All rights reserved. Short sections of text, not to exceed two paragraphs, may be quoted without explicit permission provided that full credit, including $\odot$ notice, is given to the source. 
Household Balance Sheet Channels of Monetary Policy: A Back of the Envelope Calculation

for the Euro Area

Jiri Slacalek, Oreste Tristani, and Giovanni L. Violante

NBER Working Paper No. 26630

January 2020, Revised June 2020

JEL No. E21,E52

\section{ABSTRACT}

This paper formulates a back of the envelope approach to study the effects of monetary policy on household consumption expenditures. We analyze several transmission mechanisms operating through direct, partial equilibrium channels-intertemporal substitution and net interest rate exposure - and indirect, general equilibrium channels - net nominal exposure, as well as wealth, collateral and labor income channels. The strength of these forces varies across households depending on their marginal propensities to consume, their balance sheet composition, the sensitivity of their own earnings to fluctuations in aggregate labor income, and the responsiveness of aggregate earnings, asset prices and inflation to monetary policy shocks. We quantify all these channels in the euro area by combining micro data from the HFCS and the EU-LFS with structural VARs estimated on aggregate time series. We find that the indirect labor income channel and the housing wealth effect are strong drivers of the aggregate consumption response to monetary policy and explain the cross-country heterogeneity in these responses.

Jiri Slacalek

European Central Bank

D-60640 Frankfurt am Main

Europe

jiri.slacalek@ecb.int

Oreste Tristani

European Central Bank

D-60640 Frankfurt am Main

Europe

oreste.tristani@ecb.europa.eu
Giovanni L. Violante

Department of Economics

Princeton University

Julis Romo Rabinowitz Building

Princeton, NJ 08540

and NBER

violante@princeton.edu 


\section{Introduction}

In the last few years a new literature has flourished in macroeconomics. It embeds New Keynesian elements (namely nominal rigidities) into the workhorse incomplete market framework. A central contribution of this Heterogeneous Agent New Keynesian (HANK) literature is to revisit the transmission mechanism of monetary policy (???). In Representative Agent New Keynesian models (RANK), monetary policy affects consumption expenditures because households substitute intertemporally between consumption and saving in the wake of unexpected changes in the interest rate. In HANK, this channel is small and coexists with a plethora of others. First, intertemporal substitution is not the only direct, i.e. partial equilibrium, effect. Changes in the interest rate affect household financial income differently depending on whether they are borrowers or savers (i.e. their net interest rate exposure). Indirect effects operate through the general equilibrium responses of inputs and asset prices, notably labor income and house prices. After a monetary easing, the direct increase in households' expenditure and firms' investment stimulates output, employment and wages. The additional increases in expenditure induced by higher employment and wages are the essence of the indirect effect. The strength of these indirect channels crucially depends on the size of the marginal propensity to consume (MPC), which is an order of magnitude higher in HANK models relative to RANK ones. ${ }^{1}$

The recent literature on HANK models has followed two parallel paths in order to quantify these various effects. Some authors have built rich DSGE models by adding a lot of realism on the household side to otherwise standard New Keynesian environment (???????????). Others have resorted to making simplifying assumptions that lead to analytical solutions (???????). These two approaches are complements. The first one provides a better framework for the analysis of business cycles and policy counterfactuals. The second one overcomes the computational complexity of the first and offers transparent insights about the economic forces at work.

In this paper, we follow this second approach and apply it to understand the relative strength of these numerous transmission channels of monetary policy to household spending in the euro area. In developing the theory, we closely follow ? and formulate an analytical decomposition that showcases the relevant ingredients needed for this type of back of the envelope calculation. We emphasize that the strength of all transmission channels to aggregate consumption depends on three key dimensions of households' heterogeneity: their portfolios, their exposures to aggregate fluctuations, and their marginal propensities to consume. Distinctly from ?, we argue that a useful way to summarize such complex distribution is grouping households between the non-hand-to-mouth, the wealthy hand-to-mouth and the poor hand-to-mouth (HtM) based on

\footnotetext{
${ }^{1}$ For a summary of this literature, see e.g., ? and ?.
} 
their holdings of liquid and illiquid assets as in ? and ?. ${ }^{2}$

Our estimation consists of several steps combining aggregate and household-level data for the four largest euro area countries: Germany, France, Italy, and Spain. From structural VARs, we estimate how monetary policy affects inflation, asset prices, and aggregate employment. From the EU Labor Force Survey (EU-LFS), we estimate the differential systematic sensitivity of these three groups to cyclical fluctuations. Micro data on household balance sheets and income from the Household Finance and Consumption Survey (HFCS) gives us the distribution of household portfolios. From the existing literature, we borrow estimates of the MPC out of transitory income and capital gains. We then assemble all these ingredients and, guided by our decomposition, provide a back of the envelope calculation that quantifies the impact of a surprise change in interest rates on household expenditures, separating each channel. Using the estimated response of aggregate quantities and prices from the VAR to assess the magnitudes of general equilibrium feedbacks is another key difference between our approach and that of ? and ?. ${ }^{3}$

At the euro area level we find that about 60 percent of the total increase in nondurable consumption is due to the indirect income and housing wealth/collateral channels. Quantitatively, hand-to-mouth households adjust their consumption markedly after the shock. The initial 100 basis-point cut of interest rates (80 basis points over a one-year horizon) results in an increase of consumption of almost 1 percent for the poor hand-to-mouth and of 1.8 percent for the wealthy hand-to-mouth. Spending of the non-hand-to-mouth households rises by 0.5 percent. Given their disproportionate share in consumption (about 80\%), the non-hand-to-mouth households dominate the aggregate consumption increase of 0.7 percent.

We find that the aggregate consumption response from this simple back of the envelope decomposition matches well the one independently estimated in our structural VAR.

The important role played by the indirect general equilibrium effects implies that a simple RANK model would underestimate the dynamics of aggregate consumption. The intertemporal substitution channel remains the prevalent one only for unconstrained households, and when we separate the very rich (top 10 percent) from the rest of the unconstrained, even for them the

\footnotetext{
${ }^{2}$ The way to think about these three types of households is the following. Hand to mouth households are at a kink in their budget constraint, i.e. they either hold zero liquid wealth (zero is a kink because of the spread between saving and borrowing rates) or they are at their unsecured credit limit. The difference between the two types is that the wealthy hand-to-mouth ones also hold illiquid wealth (e.g., housing) above a certain threshold. Non hand-tomouth households are all the rest, i.e. the 'unconstrained'.

${ }^{3}$ ? and ? share our same goal of estimating the response of consumer spending to monetary policy in the euro area. They do so through a rich dynamic lifecycle model (i.e. it is more similar to the first approach discussed above) where households can save in bonds and housing or stocks. Unlike us, their model generates endogenously the distribution of MPCs, while we read it off existing evidence. Like us, ? estimate the effects of monetary policy shocks on income and stock returns through a VAR external to the model. A disadvantage of using a large structural model in this context is that its computational complexity prevents them from including nominal debt and the Fisher channel as well as the housing channel (in case of ?), which we find to be important.
} 
indirect effects become dominant because of their extensive holdings of housing and stocks.

For the poor hand-to-mouth, all their increase in spending is due to the combination of three elements: (i) aggregate employment increases after the monetary easing, (ii) their labor income is especially sensitive to the cycle, and (iii) their MPC our of transitory income changes is large.

The wealthy hand-to-mouth gain from this same labor income channel. In addition, because they tend to be homeowners with large mortgages, they benefit for three reasons. After an interest rate cut, house prices rise. Also inflation rises, reducing the real value of debt. This last force, however, is quantitatively modest as a result of the well documented limited response of inflation to monetary policy in the euro area. Finally, when they hold flexible rate mortgage contracts they also take advantage from the reduction in interest payments.

The differences in homeownership rates, mortgage market institutions (prevalence of adjustable-rate mortgages) and labor market institutions imply that the strength of the transmission channels varies considerably across our four euro area economies. We mostly contrast Germany and Spain, which represent polar cases in terms of these structural factors. For example, households in Spain are almost twice as likely to own their home and also hold much more adjustablerate debt. The two countries also differ in the share of hand-to-mouth households. Over 17 percent of Spanish households are wealthy hand-to-mouth compared to 12 percent in Germany. In addition, we estimate a much stronger sensitivity of aggregate house prices and labor earnings to monetary policy in Spain than in Germany.

Because of all these differences, the income and the housing wealth/collateral effects in Spain substantially exceed their counterparts in Germany. Even the direct net interest rate exposure effect of a cut in the policy rate is large and positive in Spain, whereas it is small and negative in Germany since German households are net savers. When we add up to obtain the total effect, aggregate nondurable consumption responds very strongly in Spain (nearly 2 percent) and much less so in Germany (0.4 percent).

The rest of the paper is organized as follows. Section ?? outlines our analytical decomposition. Section ?? explains how we empirically implement this decomposition. Section ?? describes our findings. Section ?? concludes.

\section{Decomposition of effects of a monetary policy shock}

We develop an analytical decomposition of the effects of a monetary policy shock on household consumption expenditures. The derivation follows closely ?, as well as ? and ?. We proceed step by step and examine: (i) direct effects of changes in interest rates due to intertemporal substitution and (ii) net interest rate exposures, (iii) indirect labor income effects, (iv) Fisher 
effects due to the reevaluation of nominal long-term assets, and (v) effects associated with capital gains on real, less liquid, assets such as stocks and housing.

Rather than writing down a complex household problem with all these features at the same time, we separate these channels and examine each one in isolation. The gains in terms of clarity outweigh the tediousness of some repetition, we believe. We begin with the problem of non hand-to-mouth unconstrained households and next we analyze the problem of the hand-tomouth ones. This decomposition will guide our empirical exercise.

We study the effect of a purely transitory change in the (real) policy rate $R=1+r$, i.e. a one period change that has no impact on future values of the interest rate. We assume this shock is unexpected and perceived as 'once and for all', i.e. we examine what the literature often calls an MIT shock. This shock has also transitory effects on income, asset prices and inflation (but permanently changes the price level). ${ }^{4}$

To simplify the exposition, we abstract from idiosyncratic and aggregate risk. Specifically, we abstract from the fact that a monetary policy shocks can lead to fluctuations in the precautionary saving motive (and hence in current and future marginal propensity to consume) and shifts in the share of hand-to-mouth households. ${ }^{5}$ We only model the effects of monetary policy on consumption of nondurables and services, and abstract from the adjustment of durables.

Throughout the derivations, we adopt a recursive formulation and denote future variables by the 'prime' sign.

\subsection{Non-hand-to-mouth households}

Non hand-to-mouth households are those for which borrowing constraints do not bind. Thus, they are on their Euler equation for consumption and saving. We'll use this property repeatedly in the derivations below. In particular, we take the extreme view that the constraint never binds for them so they are, essentially, permanent-income consumers.

\subsubsection{Household problem and marginal propensity to consume}

We begin with a statement of the household problem and a derivation of a formula for the marginal propensity to consume (MPC). The household is infinitely lived, with intra-period utility $u(c)$, with $u^{\prime}>0$ and $u^{\prime \prime}<0$, where $c$ denote consumption expenditures. Later we specialize

\footnotetext{
${ }^{4}$ We adopt this assumption of transitory effects for simplicity, but also because the typical half life of a monetary shock is 6 months and the reference period in all our empirical analysis is a year. Persistent shocks are analyzed by ?, ? and ?.

${ }^{5}$ The precautionary saving motive at steady-state, however, could be thought of being absorbed into the level of the marginal propensity to consume which, as we discuss later, we take directly from the data. ? document moderate cyclical fluctuations in the share of hand-to-mouth households in the US.
} 
the utility function to the CRRA class and let $\gamma \geq 0$ be the coefficient of relative risk aversion. Let $b$ denote holdings of a one-period real asset, and $y$ denote household income. The future is discounted at rate $1 / \beta-1$. The recursive formulation of the household problem is:

$$
\begin{aligned}
V(b, y ; R)= & \max _{c, b^{\prime}} u(c)+\beta V\left(b^{\prime}, y^{\prime} ; \bar{R}\right) \\
& \text { s.t. } \\
b^{\prime}= & R(b+y-c)
\end{aligned}
$$

where $\bar{R}$ is the initial level of the policy rate.

The first-order condition (FOC) with respect to $c$ is

$$
u_{c}=\beta R V_{b}^{\prime}
$$

where we used the notation $V_{b}^{\prime}$ to denote $\partial V\left(b^{\prime}, y^{\prime} ; \bar{R}\right) / \partial b^{\prime}$. Totally differentiating it with respect to $c$ and $b^{\prime}$ yields:

$$
u_{c c} d c=\beta R V_{b b}^{\prime} d b^{\prime}
$$

Define the individual marginal propensity to consume for a non HtM household with states $(b, y)$ as the change in consumption induced by a change in wealth:

$$
\mu(b, y):=\frac{d c}{d b}
$$

and note that, by differentiating the budget constraint,

$$
\frac{1}{R} d b^{\prime}+d c=d b
$$

i.e. a marginal dollar of wealth can be either spent or saved. Thus,

$$
\mu:=\frac{d c}{d b}=1-\frac{1}{R} \frac{d b^{\prime}}{d b}
$$

or, the MPC (where we dropped the arguments to lighten notation) equals one minus the marginal propensity to save (MPS) adjusted by the interest rate between the two periods. Dividing (??) by $d b$, using it into the above equation and rearranging yields:

$$
\mu=\frac{R^{2} \beta V_{b b}^{\prime}}{u_{c c}+R^{2} \beta V_{b b}^{\prime}} .
$$




\subsubsection{Direct effects}

We begin by considering the effect of a transitory change in $R$ on $c$, keeping $y$ constant, i.e. what the literature calls the direct effect of monetary policy. Combining the FOC (??) and the budget constraint yields

$$
u_{c}=\beta R V_{b}^{\prime}\left(R(b+y-c), y^{\prime} ; \bar{R}\right) .
$$

Differentiating with respect to $R$ and $c$ yields

$$
u_{c c} d c=\beta V_{b}^{\prime} d R+\beta R V_{b b}^{\prime}(b+y-c) d R-R^{2} \beta V_{b b}^{\prime} d c
$$

and note that the value function $V^{\prime}$ depends on $R$ only through $b^{\prime}$ since next period the interest rate returns to $\bar{R}$. Using the FOC (??) in the first term of the right hand side (RHS) and dividing through by $u_{c c}(c)$ yields:

$$
d c\left[1+\frac{R^{2} \beta V_{b b}^{\prime}}{u_{c c}}\right]=\frac{u_{c}}{u_{c c}} \frac{d R}{R}+\frac{R^{2} \beta V_{b b}^{\prime}}{u_{c c}}(b+y-c) \frac{d R}{R} .
$$

Substituting (??) into the left-hand side and using the approximation $d R / R \simeq d r$ yields:

$$
d c=\frac{u_{c}}{u_{c c}}(1-\mu) d r+\mu(b+y-c) d r .
$$

From the definition of the elasticity of substitution for CRRA utility $1 / \gamma:=-\frac{u_{c}}{u_{c c} c}$ we obtain:

$$
d c^{D I R}=-\frac{1}{\gamma}(1-\mu) c d r+\mu(b+y-c) d r .
$$

The first term captures the intertemporal substitution effect (IES). An increase in $r$ induces households to save more, by postponing consumption from today into the future. The substitution effect increases in the value of the elasticity of intertemporal substitution $1 / \gamma$ and the value of the marginal propensity to save $(1-\mu)$. The second term captures net exposure to the interest rate. An increase in $r$ induces a positive income effect if the household is a net saver $(b+y>c)$ and a negative income effect if it is a borrower. The size of the income effect is proportional to the MPC $\mu$.

Long-term liquid assets. So far we have assumed that $b$ is a short term (one-period) liquid asset. Generalizing this derivation to long-term liquid assets and liabilities is immediate. Suppose that a fraction $\delta^{B}$ of assets $B$ and a fraction $\delta^{\ell}$ of liabilities $\ell$ matures every period. The most relevant 
example, in our context, is adjustable rates mortgages (ARMs). ${ }^{6}$ Then, it is easy to see that the formula in (??) can be generalized to:

$$
d c^{D I R}=-\frac{1}{\gamma}(1-\mu) c d r+\mu\left[(b+y-c)+\delta^{B} B-\delta^{\ell} \ell\right] d r,
$$

The last three terms in (??), combined in the squared bracket, form what? calls the net interest rate exposure effect (NIE) of monetary policy, thus:

$$
d c^{D I R}=d c^{I E S}+d c^{N I E} .
$$

\subsubsection{The indirect general equilibrium effects on income}

Instead of fixing $y$, we now allow labor income $y$ to be affected by $r$. This channel captures the idea that changes in the interest rate can have so-called 'aggregate demand effects', for example because of the presence of nominal rigidities. An initial impulse to expenditures raises labor demand and earnings, pushing up expenditures further through an equilibrium multiplier effect. ${ }^{7}$

Since we only consider transitory changes in $r$, future income $y^{\prime}$ is unaffected. ${ }^{8}$ Returning to equation (??) and differentiating with respect to $c$ and $y$ we arrive at:

$$
\left[u_{c c}+R^{2} \beta V_{b b}^{\prime}\right] d c=R^{2} \beta V_{b b}^{\prime} d y .
$$

From the definition of the MPC in (??), we obtain:

$$
d c^{I N C}=\mu d y,
$$

where the last term is the indirect labor income effect (INC). Note that the change in labor income translates into consumption proportionately to the MPC $\mu$.

To put more structure on this term, let $\varepsilon_{y, Y}$ be the elasticity of individual income to aggregate income. Individuals differ in their age, education, location, industry, occupation, skill level, etc., and all these characteristics determine a different degree of exposure to aggregate fluctuations. ${ }^{9}$

\footnotetext{
${ }^{6}$ The reduction of interest payments on adjustable rate long term debt is often called in the literature cash-flow effect. See, .eg., ?, ? and ?.

${ }^{7}$ Even in absence of nominal rigidities, a lower interest rate may expand investment, therefore increasing the capital stock, the marginal product of labor and the wage.

${ }^{8}$ Sticky prices slow down dynamics. Our implicit assumption is that, within the time horizon we consider -one year- prices, and thus income, have fully adjusted.

${ }^{9}$ These individual elasticities $\varepsilon_{y, Y}$ have to satisfy the aggregate consistency condition stating that when they are summed across all individuals with weights equal to $y / Y$ (the individual income share of the total), such sum equals to one.
} 
Then, another useful way to write (??) is

$$
d c^{I N C}=\mu \varepsilon_{y, Y}\left(\frac{y}{Y}\right) d Y .
$$

The change in aggregate income produced by the monetary policy shock passes through to consumption proportionately to the marginal propensity to consume $\mu$, the sensitivity of individual to aggregate income $\varepsilon_{y, Y}$ and the individual share of total income $y / Y$. As discussed in ? and ?, unequal incidence of aggregate fluctuations across the population can be a source of dampening or amplification of macro shocks, depending on the covariance between exposure and MPC across consumers.

\subsubsection{Fisher effects through nominal long-term debt}

We now extend the household problem to incorporate nominal long-term debt (namely, mortgages). ${ }^{10}$ The problem becomes:

$$
\begin{aligned}
V(b, y, m ; R, p)= & \max _{c, b^{\prime}} u(c)+\beta V\left(b^{\prime}, y^{\prime}, m^{\prime} ; \bar{R}, p^{\prime}\right) \\
& \text { s.t. } \\
b^{\prime}= & R\left(b+y-c-\frac{\delta^{m} m}{p}\right) \\
m^{\prime} & =\left(1-\delta^{m}\right) m
\end{aligned}
$$

where $m$ is a geometrically decaying stock of nominal debt whose fraction $\delta^{m}$ matures every period, and $p$ is the aggregate price level. Since we have already analyzed interest exposure effects earlier, here we assume without loss of generality that the interest rate on these nominal liabilities is zero and focus on the impact of the policy shock on the price level. ${ }^{11}$ We do not allow the household to adjust $m$ (i.e. we assume refinancing away), but given the focus on a transitory change in the policy rate and the well known frictions in refinancing, this simplification is rather innocuous. ${ }^{12}$

The household's FOC becomes:

$$
u_{c}=\beta R V_{b}^{\prime}\left(R\left(b+y-c-\frac{\delta^{m} m}{p}\right), y^{\prime}, m^{\prime} ; \bar{R}, p\right),
$$

\footnotetext{
${ }^{10}$ We note that if long-term debt is nominal, like in the case of most long-term mortgage contracts with adjustable rates, then $\ell$ and $\delta^{\ell}$ in Section ?? would equal, respectively, the real value of the contract $m / p$ and its maturity parameter $\delta^{m}$ in this section.

${ }^{11}$ The timing we adopted, for convenience, is that the mortgage payment is made at the beginning of the period, at the same time as consumption expenditures.

12?, ? and ?, among others, study the effects of monetary policy through refinancing.
} 
where, we have used the fact that, since the price level changes permanently within the period, $p^{\prime}=p$. This rise in the price level will lead to a re-evaluation effect on debt. Differentiating this last equation with respect to $c$ and $p$ :

$$
u_{c c} d c=-\beta R^{2} V_{b b}^{\prime} d c+\beta R^{2} V_{b b}^{\prime}\left(\frac{\delta^{m} m}{p}\right) \frac{d p}{p}+\beta R V_{b p}^{\prime}\left(b^{\prime}, y^{\prime}, m^{\prime} ; \bar{R}, p\right) d p
$$

Combining the Envelope condition $u_{c}=V_{b}$ with (??) evaluated at steady state, forwarding one period and differentiating with respect to $p$ :

$$
V_{b p}^{\prime}=\beta \bar{R}^{2} V_{b b}^{\prime \prime} \frac{\delta^{m}\left(1-\delta_{m}\right) m}{p^{2}}+\beta \bar{R} V_{b p}^{\prime \prime}
$$

Note that $V_{b b}^{\prime \prime}=V_{b b}^{\prime}$ (and similarly for the subsequent periods) because the environment is stationary after the period of the shock. Under the assumption $\beta \bar{R}=1$ we can substitute out recursively the cross derivative of the value function to arrive at

$$
V_{b p}^{\prime}=\bar{R} V_{b b}^{\prime} \frac{\delta^{m} m}{p^{2}} \sum_{j=1}^{\infty}\left(1-\delta_{m}\right)^{j}
$$

which combined with (??) yields

$$
u_{c c} d c=-\beta R^{2} V_{b b}^{\prime} d c+\beta R^{2} V_{b b}^{\prime}\left(\frac{\delta^{m} m}{p}\right) \frac{d p}{p}+\beta R \bar{R} V_{b b}^{\prime}\left(\frac{\left(1-\delta_{m}\right) m}{p}\right) \frac{d p}{p} .
$$

For small deviations of the interest rate from steady-state, $R / \bar{R} \simeq 1$, and with the normalization $p=1$ we obtain

$$
d c^{N O M}=\mu m d p
$$

This is what the literature calls the Fisher effect (NOM). An interest rate cut that generates inflation (a permanent rise in the price level $d p$ ) reduces the real value of debt. The extent to which current consumption responds to this re-evaluation effect depends on the size of the outstanding nominal liabilities and on the MPC.

\subsubsection{Effects through capital gains on real (less liquid) assets}

We now allow the household to hold a real asset $k$ such as stocks or housing. Let $q$ be the relative price of this asset and normalize its dividend to zero. We assume that only a fraction $\lambda<1$ of households react to this price change and, when they do, they must pay a fixed transaction cost $\tau>0$ to adjust their stock of $k$. Let $\Delta>0$ be withdrawals from the illiquid asset for the purpose 
of reallocating funds into liquid wealth $b$ or consuming it. ${ }^{13}$ The household problem becomes:

$$
\begin{aligned}
V(b, y, k ; R, q)= & \max _{c, b^{\prime}, k^{\prime}} u(c)+\beta V\left(b^{\prime}, y^{\prime}, k^{\prime} ; \bar{R}, \bar{q}\right) \\
& \text { s.t. } \\
b^{\prime}= & R(b+y-c+\Delta) \\
q k^{\prime}= & q k-\Delta-\tau \mathbb{I}_{\{\Delta>0\}} \\
\Delta \leq & \theta q k
\end{aligned}
$$

where the last inequality is a collateral constraint stating that the maximum amount that can be withdrawn is a fraction $\theta$ of the value of the asset. Note that, because the change in $R$ is transitory, also $q$ returns to its steady state value after the first period.

Consider a household who adjusts its portfolio (i.e. at the optimum $\Delta>0$ ) and whose collateral constraint is not binding. We can split its problem between the consumption/saving decision in the first stage and the allocation of saving between the two assets in the second stage. Let total financial wealth next period be $x^{\prime}=b^{\prime}+q k^{\prime}$. The first-stage of the problem above, when all wealth is temporarily liquid, can be therefore restated (with a slight abuse of notation for $V$ ) as:

$$
\begin{aligned}
V(b, y, k ; R, q)= & \max _{\substack{c, x^{\prime} \\
\text { s.t. }}} u(c)+\beta V\left(x^{\prime} ; \bar{R}, \bar{q}\right) \\
x^{\prime}= & R(b+y-c+q k) .
\end{aligned}
$$

Differentiating the Euler equation

$$
u_{c}=\beta R V_{x}^{\prime}\left(R(b+y-c+q k), y^{\prime} ; \bar{R}, \bar{q}\right)
$$

with respect to $c$ and $q$, keeping in mind that the effect of a change in the policy rate $r$ on $q$ is transitory, we obtain

$$
u_{c c} d c=-\beta R^{2} V_{x x}^{\prime} d c+\beta R^{2} V_{x x}^{\prime} k d q .
$$

Rearranging, and taking into account that only a fraction $\lambda$ adjusts following the capital gain, yields the average change for the holders of the real asset:

$$
d c^{C A P}=\lambda \mu k \cdot d q
$$

\footnotetext{
${ }^{13}$ We focus on the case of a withdrawal $(\Delta>0)$, but the derivation holds for deposits $(\Delta<0)$ as well.
} 
where, without loss of generality we have normalized $q=1$.

The key observation is that the MPC out of a capital gain in illiquid wealth $\lambda \mu$ is smaller than the MPC out of a transitory liquid wealth/labor income change for non hand-to-mouth households (simply $\mu$ ), because not everyone responds to the price change. This feature of the model is consistent with the empirical evidence on MPCs out of different types of windfall incomes.

We conclude by noting that, in the context of housing, this calculation is likely to provide an upper bound for the effect of a rise in prices for two reasons. First, as discussed by ?, the more transitory the price change, the higher the impact on consumption since more households would adjust (i.e. $\lambda$ is larger). Second, we are abstracting from the fact that some households expect to be homeowners in the future and, as a result of the higher house price, they need to cut expenditures to afford the same housing consumption in the future. This bias, however, is smaller the more transitory the price change is.

\subsubsection{Summary}

Combining all the pieces together, for a non hand-to-mouth household (denoted with subscript $n$ ) the consumption response at impact to a transitory monetary policy shock is:

$$
d c_{n}^{T O T}=d c_{n}^{I E S}+d c_{n}^{N I E}+d c_{n}^{I N C}+d c_{n}^{N O M}+d c_{n}^{C A P},
$$

which can be unfolded as:

$$
\begin{aligned}
\frac{d c_{n}^{\text {TOT }}}{d r}= & -\frac{1}{\gamma}(1-\mu) c_{n}+\mu\left[\left(b+y-c_{n}\right)+\delta^{B} B-\delta^{\ell} \ell\right] \\
& +\mu \varepsilon_{y, Y}\left(\frac{y}{Y}\right) \frac{d Y}{d r} \\
& +\mu \cdot m \cdot \frac{d p}{d r} \\
& +\lambda \mu k \cdot \frac{d q}{d r} .
\end{aligned}
$$

\subsection{Hand-to-mouth households}

We now develop an analogous derivation for poor and wealthy hand-to-mouth households. We assume that the constraints that these households face before the shock are still binding after the shock (i.e. the shock is small).

Poor hand-to-mouth. Since they are not on their Euler equation, direct intertemporal substitution effects are zero for the poor HtM. Their consumption is fully determined by the budget 
constraint with $b$ and $b^{\prime}$ set at the value of their unsecured credit limit $\underline{b}$. If we also allow for some holdings of nominal debt $m$ with maturing portion $\delta^{m}$, we obtain:

$$
c=y-\underline{b} r-\frac{\delta^{m} m}{p}
$$

Differentiating the budget constraint with respect to $c$ and $R$, we obtain

$$
d c_{p}^{N I E}=-\underline{b} d r
$$

Comparing (??) to the net interest rate exposure channel for non HtM, (??), the key difference emerging is the value of the MPC, which is equal to one for the HtM. Differentiating the budget constraint with respect to $c$ and $p$, and normalizing the initial price level $p$ to 1 yields:

$$
d c_{p}^{N O M}=\delta^{m} m d p
$$

i.e. for this group the Fisher effect only applies to the currently maturing portion of debt, mediated by an MPC equal to one. The indirect income effect, equal to (??), is the only other force active for poor HtM households. It is easy to see that differentiating the budget constraint with respect to $c$ and $y$ we obtain

$$
d c_{p}^{I N C}=\varepsilon_{y, Y}\left(\frac{y}{Y}\right) d Y
$$

and thus, collecting these three channels the total consumption response of this group can be summarized as:

$$
d c_{p}^{T O T}=d c_{p}^{N I E}+d c_{p}^{I N C}+d c_{p}^{N O M}
$$

or, unfolded,

$$
\begin{aligned}
\frac{d c_{p}^{T O T}}{d r}= & -\underline{b} \\
& +\varepsilon_{y, Y}\left(\frac{y}{Y}\right) \frac{d Y}{d r} \\
& +\delta^{m} m \frac{d p}{d r} .
\end{aligned}
$$

Note that, as explained above, some poor hand-to-mouth households are at the zero kink in their budget constraint. Since they have no debt, for this subgroup, $d c_{p}^{N I E}=d c_{p}^{N O M}=0$.

Wealthy hand-to-mouth. Direct intertemporal substitution effects are zero also for the wealthy HtM. Since these households might have adjustable rate mortgages in their portfolios besides 
unsecured debt, their net interest rate exposure component becomes

$$
d c_{p}^{N I E}=\left(-\underline{b}-\delta^{\ell} \ell\right) d r .
$$

Fisher and indirect income effects are exactly as for the poor HtM. Because they own some illiquid assets, effects through capital gains are operational for this type of households. In particular, for these households collateral constraints tend to bind, or they would borrow more to consume more. A constrained household can take advantage of a price change only to the extent that a rise in the value of collateral relaxes its credit limit and allows him to tap into its illiquid wealth. As before let $\lambda$ be the fraction of households adjusting. Assume that the collateral constraint

$$
\Delta \leq \theta q k
$$

is binding. The version of the budget constraint in (??) for a wealthy HtM household is therefore:

$$
c=y+\theta q k
$$

Differentiating the above equation with respect to $c$ and $q$, and accounting for the fact that only a share $\lambda$ of households taps into their illiquid wealth, yields (after the normalization $q=1$ ):

$$
d^{C A P}=\lambda \theta k \cdot d q
$$

thus $\lambda \theta$ is, effectively, the marginal propensity to consume out of the capital gain for this group.

In conclusion, the total consumption response for a wealthy HtM household is:

$$
d c_{w}^{T O T}=d c_{w}^{N I E}+d c_{w}^{I N C}+d c_{w}^{N O M}+d c_{w}^{C A P}
$$

which can be unfolded as:

$$
\begin{aligned}
\frac{d c_{w}^{T O T}}{d r}= & -\underline{b}-\delta^{\ell} \ell \\
& +\varepsilon_{y, Y}\left(\frac{y}{Y}\right) \frac{d Y}{d r} \\
& +\delta^{m} m \frac{d p}{d r} \\
& +\lambda \theta k \cdot \frac{d q}{d r} .
\end{aligned}
$$

This concludes our theoretical decomposition. We now turn to its empirical implementation. 


\section{Empirical implementation}

In practice, we want to measure the impact of a monetary policy shock on non-durable expenditures in the first year after the shock.

We follow the strategy adopted for the decomposition and assume that the bulk of the heterogeneity in the population which is relevant for the monetary policy transmission can be captured by three groups of households: (i) non-hand-to-mouth, (ii) poor hand-to-mouth, and (iii) wealthy hand-to-mouth.

The idea that we leveraged in the decomposition is that HtM households face frictions which make their consumption decision insensitive to changes in the interest rate, but highly sensitive to transitory changes in income. On the contrary, the non HtM are permanent income consumers and thus are insensitive to transitory income shocks but, being on their Euler equation, they are responsive to changes in the real rate. In addition, these three hand-to-mouth groups differ in the structure of their balance sheet and, potentially, in their degree of exposure to aggregate income fluctuations. As clear from our discussion of Section ??, these features are central to the decomposition.

For each HtM type, we need a number of ingredients. To calculate the intertemporal substitution channel, we need values for the IES $1 / \gamma$ and the MPCs $\mu$, which we obtain from the existing empirical literature. To compute portfolio exposure to fluctuations in the interest rate, we need a measure of liquid wealth $(b)$ and saving, which we construct by combining data from the HFCS with National Accounts data. We measure the indirect labor income effect in two steps. First, we estimate the impact of a monetary policy shock on aggregate earnings through a structural VAR. Second, we estimate the sensitivity $\varepsilon_{y, Y}$ of labor income of each group to aggregate fluctuations from the EU Labour Force Survey (LFS) data, as done by in ?, ? and ? for the US. To compute the transmission through long-term nominal debt, we use HFCS data on household portfolios jointly with VAR evidence on the impact of a monetary policy shock on inflation. To calculate the effects occurring through capital gains, we again estimate the effects of monetary policy shocks on asset prices (stocks and housing) through the same VAR, and obtain values of the MPC out of stocks and housing from the literature.

We obtain the total impact of a monetary policy shock on consumption by aggregating the consumption response of the three groups weighted by their expenditures shares. Upon aggregating, we do not impose any equilibrium condition. In particular, we do not impose $C=Y$, as done by ? and by (?) in their analysis of monetary transmission in the representative agent and in the two-agent New Keynesian model. While this condition establishes some internal consistency, it does so only for a closed economy without capital. Instead, we opt for subsuming 
Figure 1: Share of Hand-to-Mouth Households, Percent
(a) Share of HtM Households Across Countries
(b) Share of HtM Households by Age

Source: Eurosystem Household Finance and Consumption Survey, wave 2

Note: The left panel shows the shares of poor and the wealthy hand-to-mouth households in the euro area (EA) and in the four largest euro area countries, Germany (DE), Spain (ES), France (FR) and Italy (IT). The right panel shows the shares of poor and the wealthy hand-to-mouth households in the euro area by age of the reference person. Households are classified based on their holdings of net liquid and illiquid wealth following ?. See section ?? for details.

all equilibrium relationships of the economy in the empirically estimated VAR that yields the change in $p, Y$ and $q$ after a shock to $r$.

The next two sections contain a detailed explanation of all the steps outlined above. All our calculations are done separately for each of the four major countries in the euro area, Germany (DE), Spain (ES), France (FR) and Italy (IT), as well as for the weighted aggregate of these four which we call the 'Euro Area.'

\subsection{Classification of households by hand-to-mouth status}

We follow ? and define the three groups based on their holdings of net liquid and illiquid wealth. Poor hand-to-mouth households are those with zero or negative illiquid wealth and net liquid assets close to zero or to the credit limit. Wealthy hand-to-mouth households share the previous definition for liquid assets, but have positive holdings of net illiquid assets. Non hand-to-mouth are the residual group. Here, by close we mean no more than half of their monthly disposable labor income away from zero (if they hold positive liquid wealth) or from the credit limit (if they hold positive liquid wealth). See Appendix ?? for further details.

Figure ??(a) shows the shares of the poor and the wealthy hand-to-mouth households in the euro area and in the four largest euro area countries. At the euro area level, about $10 \%$ of households are classified as poor hand-to-mouth and about $12 \%$ of households are wealthy hand-to-mouth. The overall share of hand-to-mouth households is quite stable across the four largest euro area countries. Also its split between the two types is similar across countries, with the exception of Spain where wealthy HtM are much more prevalent. This feature is explained by home ownership rates: 83 percent of Spanish households are homeowners, twice as many as in Germany. ${ }^{14}$

We therefore confirm the finding of ? that in continental Europe the share of HtM households is smaller than in the US. What accounts for this discrepancy is the share of the wealthy HtM —around $20 \%$ in the US - whereas the share of poor HtM is approximately the same. ${ }^{15}$

The shares of the poor and the wealthy hand-to-mouth vary substantially with age (Fig-

\footnotetext{
${ }^{14}$ Also in Italy homeownership is very high, but the majority of Italian households are outright owners without
} 
Figure 2: Net Liquid Assets and Net Wealth by Hand-to-Mouth Status, Median, EUR Thousands
(a) Net Liquid Assets
(b) Net Wealth

Source: Eurosystem Household Finance and Consumption Survey, wave 2

Note: The left panel shows net liquid wealth. Liquid assets consist of deposits, mutual funds, bonds and stock; liquid liabilities consist of overdraft debt and credit card debt. The right panel shows net wealth which includes all real (including housing) and financial assets net of all other liabilities. See section ?? for details.

ure ??(b)). For poor HtM, it is declining with age, from 15\% for households below 35 to $7 \%$ for households above 75. In contrast, the share of the wealthy HtM follows a hump-shaped profile, peaking at $15 \%$ around age 50, and declining thereafter. This pattern is linked to home ownership: young home owners face regular large mortgage payments which absorb most of their available liquid resources, and only after the age of 50 start accumulating savings again. Overall, these facts imply that poor HtM are predominantly young, wealthy HtM mainly middle-aged, and non-HtM chiefly older households. Thus, the effects of monetary policy we analyze below can also be related to age.

The three groups of households differ significantly in their holdings of liquid and illiquid assets. As illustrated in Figure ??, the non HtM households hold substantial liquid and illiquid wealth, the euro area medians being respectively EUR 11,000 and 146,000. By definition the poor HtM households hold almost no net wealth. The wealthy HtM hold significant net illiquid assets (their median in the euro area is EUR 90,000) but virtually no liquid wealth.

Because of these differences in portfolio composition, the marginal propensities to consume for HtM households substantially exceed those for the remaining households. Next, we turn to the measurement of these MPCs.

\subsection{Evidence on heterogeneity in marginal propensities to consume out of income and wealth}

The recent empirical evidence on the MPC exploits various methodologies (quasi-experimental variation, covariance restrictions on longitudinal income and consumption data, self-reported MPCs from household surveys). This body of evidence has uncovered (i) large values for the average MPC out of transitory income and (ii) considerable cross-sectional heterogeneity. A key dimension of this heterogeneity is holdings of liquid assets. While households that are in some way 'constrained' (e.g., have no saving and costly access to credit as well as to their illiquid wealth, when they own some) are especially sensitive to transitory shocks and have high

much leftover mortgage debt.

${ }^{15}$ Institutional differences in access to credit or in the nature of income risk could be some of the culprits, but we are not aware of a systematic investigation of this question in the literature. 
Table 1: Calibration of Marginal Propensities to Consume out of Income and Wealth

\begin{tabular}{lccc}
\hline & \multicolumn{3}{c}{ Marginal Propensity to Consume } \\
\cline { 2 - 4 } Household Type & \multicolumn{3}{c}{ Collateral } \\
Poor Hand-to-Mouth & 0.50 & - & - \\
Wealthy Hand-to-Mouth & 0.50 & 0.07 & 0.07 \\
Non-Hand-to-Mouth & 0.05 & 0.01 & 0.01 \\
\hline
\end{tabular}

Notes: The table shows the calibrated values of the marginal propensities to consume out of transitory income, collateral / housing wealth and stock market wealth.

marginal propensities to consume out of income, households with adequate liquid assets are well-insured and do not materially respond. See, e.g., the reviews of the empirical literature by ?, ? , Table 1, and ? , Table $1 .^{16}$

Based on this extensive evidence, an average annual MPC out of income windfalls of $20 \%$ for the US economy appears to be a conservative choice. ${ }^{17}$ If we fix the MPC of the non HtM to $5 \%$ and assume that the nondurable consumption share of HtM households is 0.25 (as documented by ?), we obtain a value for the annual MPC for HtM households of 0.65 . Once again, we stay on the conservative side and choose a value of $0.50 .{ }^{18}$ Given the lack of systematic evidence for the euro area, we adopt these estimates in our calculation (Table ??).

To compute the formulas from Section ??, we also need MPCs out of housing and stock market wealth. Estimates of the annual average MPC out of wealth tend to be an order of magnitude smaller than estimates out of transitory income, typically around 5\% for the US. Low-liquidity households are those responsible for most of the effects for both housing and financial wealth (for recent evidence, see ??). ${ }^{19}$ Stock market wealth tends to be more liquid than housing wealth (which would imply higher MPCs), but also more volatile (which would imply lower MPCs). Overall, the consumption response to stock market capital gains is estimated to be somewhat smaller, but differences are seldom significant. The literature also finds that in continental Europe the consumption response to housing capital gains is smaller than in the US and the UK

\footnotetext{
${ }^{16}$ See also, e.g., ?, ?, ?, ?, and ?.

${ }^{17}$ This value refers to nondurable purchases. The literature (e.g., ??) also estimates MPCs for total consumption and finds substantially larger values.

${ }^{18}$ We note that, in the stylized theoretical model above, the MPC for hand-to-mouth households is always equal to 1 , but that is simply because we wanted to draw a stark distinction between different types of households and made assumptions that lead to that outcome.

${ }^{19}$ For housing, much of the literature emphasizes the importance of the housing collateral channel that also features in our decomposition (?).
} 
(?), possibly due to more rigid mortgage market institutions that make equity withdrawals more costly. For example? estimates an annual MPC out of wealth of $3 \%$ in the euro area.

In light of these findings, we set the average MPC out of housing and stock-market wealth for Europe to 0.025 (around half of the US estimate and in the low range of European estimates). We set the MPC for non hand-to-mouth to 0.01. As a result, the MPC for the HtM (computed residually as we did for income) must be around $7 \%{ }^{20}$

We conclude by emphasizing that, even though here we treat the MPC as a parameter, we are well aware that it is an endogenous object and, as such, it is not invariant to the macroeconomic environment. Our approach is based on the presumption that the estimates in Table ?? represent the current distribution of MPCs in these countries and that a small temporary shock to the interest rate would not change the average MPC for these groups.

\subsection{Intertemporal substitution and consumption-income ratios}

We set the intertemporal elasticity of substitution $1 / \gamma$, a parameter only relevant for non HtM households, to 0.5 based on the extensive reviews of the literature by ? and ?.

The decomposition in equation (??) for non HtM households needs an estimate of their consumption-income ratio. ${ }^{21}$ Unfortunately, the HFCS has neither (complete) information on consumption nor on saving flows. We therefore infer the consumption-income ratio for this group of households by matching the aggregate consumption-income ratio from National Accounts given that (i) we know their income shares from the HFCS and (ii) we also know that $c=y$ for all other constrained households. We arrive at nondurable consumption-income ratios around 70$80 \%$ for the non HtM, depending on the country; see the top panel of Table ?? (and Appendix ?? for details).

\subsection{VAR evidence on aggregate effects of monetary shocks}

To identify monetary policy shocks, we adopt an approach which is closely related to the use of high-frequency interest rate surprises as external instruments (?). The approach requires a dataset of high-frequency financial-market surprises occurring after the policy announcements following the meetings of the Governing Council of the ECB. We rely on the Euro Area Monetary Policy Event Study Database constructed in?, which reports changes in the median price of various financial assets observed in a close interval around the monetary policy meetings. More

\footnotetext{
${ }^{20}$ Other useful references in the literature on wealth effects are, e.g., ?, ? and ? for the US, and ?, ?, ?, and ? for European countries.

${ }^{21}$ Then, given their income which is available from the HFCS, we can compute $y-c$.
} 
Table 2: Consumption-Income Ratios, Aggregate Responses to Monetary Policy Shock and Unequal Income Incidence

\begin{tabular}{|c|c|c|c|c|}
\hline \multirow[b]{2}{*}{ Variable } & \multicolumn{4}{|c|}{ Country } \\
\hline & Germany & Spain & France & Italy \\
\hline Aggregate Personal Saving Rate (Percent) & 16.7 & 9.2 & 14.0 & 11.0 \\
\hline Aggregate Durables Consumption Share (Percent) & 11.2 & 5.4 & 8.0 & 6.9 \\
\hline \multicolumn{5}{|c|}{ Implied Consumption-Income Ratios for Non-HtM Households } \\
\hline Total Consumption (Percent) & 79.5 & 89.0 & 83.7 & 87.2 \\
\hline Nondurables Consumption (Percent) & 70.1 & 84.2 & 77.0 & 81.2 \\
\hline \multicolumn{5}{|l|}{ Summary of VAR Impulse Responses } \\
\hline Initial Policy Interest Rate Change (b.p.) & \multicolumn{4}{|c|}{-100} \\
\hline Policy Interest Rate Change, Four-Quarter Average (b.p.) & \multicolumn{4}{|c|}{-80} \\
\hline Earnings (Percent) & 0.5 & 1.6 & 0.7 & 1.8 \\
\hline House Prices (Percent) & 0.0 & 5.0 & 0.3 & 1.4 \\
\hline Stock Prices (Percent) & 27.0 & 21.0 & 24.0 & 26.0 \\
\hline Inflation (p.p.) & 0.1 & 0.6 & 0.3 & 0.1 \\
\hline \multicolumn{5}{|c|}{ Sensitivity of Household Employment to Aggregate Employment by HtM Status } \\
\hline Poor Hand-to-Mouth & 1.7 & 2.7 & 1.6 & 2.1 \\
\hline Wealthy Hand-to-Mouth & 0.3 & 1.6 & 1.3 & 1.6 \\
\hline Non Hand-to-Mouth & 1.1 & 0.8 & 0.9 & 0.8 \\
\hline
\end{tabular}

Notes: The table shows estimated responses of aggregate variables to a 100-bp cut in interest rates. The personal saving rate and the share of nondurables consumption on total consumption average of years 2013-2015. The bottom panel summarizes the estimates from Figure??.

specifically, ? takes into account that two information releases take place on these days: at 13.45 Central European Time the ECB issues a press release providing a summary of the policy decision and at 14.30 there is a press conference where the President explains the rationale for the decision.

We interpret changes in financial asset prices as caused by monetary policy if they occur in the time interval between the press release and the press conference, that is, in the window going from 13.25-13.35 to 15.40-15.50.22 The underlying assumptions are that, within this time interval, asset price changes are not systematically affected by other news and monetary policy does not respond to asset price changes. ${ }^{23}$ The specific yield changes that we focus on in our

\footnotetext{
22? rely on price observed over a certain interval rather than at a particular point in time to minimize the risk of measurement error.

${ }^{23}$ ? also use more refined measures of policy shocks based on only the press release or only the press conference
} 
paper refer to Overnight Index Swap (OIS) rates of 1, 3, 6-month and 1 to 10-year maturities. ? report that intraday OIS data are very noisy in the first years of EMU. We therefore ignore 1999 data in estimation.

In reality, monetary policy shocks may also include "forward guidance" information about future changes in policy rates. To abstract from the latter shocks, we proceed following the approach of ?. We estimate latent factors from changes in yields, select the first two factors, and rotate them to ensure that the second one is orthogonal to the first and does not load on the 1-month OIS. We can therefore interpret the second factor as a forward guidance factor. In our analysis, we focus on the first factor, which represents the current policy surprise. ${ }^{24}$ We sum all the intra-day surprises (summarized by the first factor) that occur in given quarter to obtain a quarterly indicator of monetary policy shocks, $s_{t}$.

We introduce the indicator $s_{t}$ directly in a quarterly VAR. The key restriction is that $s_{t}$ is not affected contemporaneously by shocks to any of the other VAR variables. This assumption is justified because $s_{t}$ is measured in a narrow time window. ${ }^{25}$

Beyond the monetary policy surprise indicator, we include in the VAR the following variables: the 3-month nominal interest rate, a commodity price index and, for each of the four countries that we consider in our analysis - Germany, France, Italy and Spain - a house price index, a consumer price index, real GDP, non-durable consumption, a stock price index, the employment rate, wages, the volume of bank lending and a measure of lending rates. The 3-month interest rate, the employment rate and lending rates are measured in annualized percentage terms. All other variables enter the VAR in log-levels.

Given the large number of country-specific variables, we rely on Bayesian estimation methods and use the priors of ?. We generate draws from the posterior using the Gibbs sampler.

Our sample period runs from 2000:Q1 to 2014:Q4. We stop in 2014:Q4 because the ECB started its program of large-scale purchases of euro area government bonds in January 2015. As of 2015, bond price changes around monetary policy announcements are less likely to be related to the setting of standard policy rates, that are the object of interest for us. All in all, we are therefore left with a short sample period. Our results should be interpreted as indicative of the likely dynamics of selected macroeconomic variables in response to monetary policy shocks. They could be revised and updated once longer time series of data become available.

Figure ?? reports impulse responses of selected variables to an identified monetary policy windows.

${ }^{24}$ Using directly the change in the 1-month OIS rate directly as the current policy surprise makes no substantive difference.

${ }^{25}$ This approach to implement the high-frequency identification is also followed by ?. That paper also proposes an alternative identification strategy capable of disentangling policy shocks proper from possible central bank information shocks. We abstract from this distinction in our analysis. 
shock leading to a fall of the 3-month nominal interest rate by 100 basis points at impact. The solid line shows median responses over 50,000 draws, the darker bands span the 16-84 percentiles of the draws distribution, the lighter bands cover the percentiles from 5 to 95 . By and large, impulse responses are only occasionally different from zero from a statistical viewpoint (focusing on the 16-84 percentiles bands). This is to be expected, given our reliance on a highfrequency identification scheme within a large VAR with quarterly data.

There is no commonly agreed benchmark analysis of the effects of ECB monetary policy shocks on individual euro area countries. The broad message from available multi-country studies, where policy shocks are often identified through a Cholesky ordering, is that impulse responses are quite heterogeneous across countries. This is also the gist of our results. For example, employment rates rise in all countries, but in Spain more so than elsewhere. Similarly, after an initial drop, house prices go up markedly in Spain, but they are much flatter in Germany. This finding is in line with ?, ? and ?, who investigate the role of the 'housing transmission channel' and estimate that the monetary policy responses of house prices are stronger in countries where households hold more mortgage debt and mortgage contracts are predominantly flexible rate, such as Spain. ?, Figure 8 estimate a semi-elasticity of house prices to interest rates around -4 for Spain and ten times smaller for Germany, in line with our findings. We also uncover large responses of stock prices to monetary policy shocks. For stock prices, the size of the estimates reported in the literature varies substantially (see ?, for a survey). 


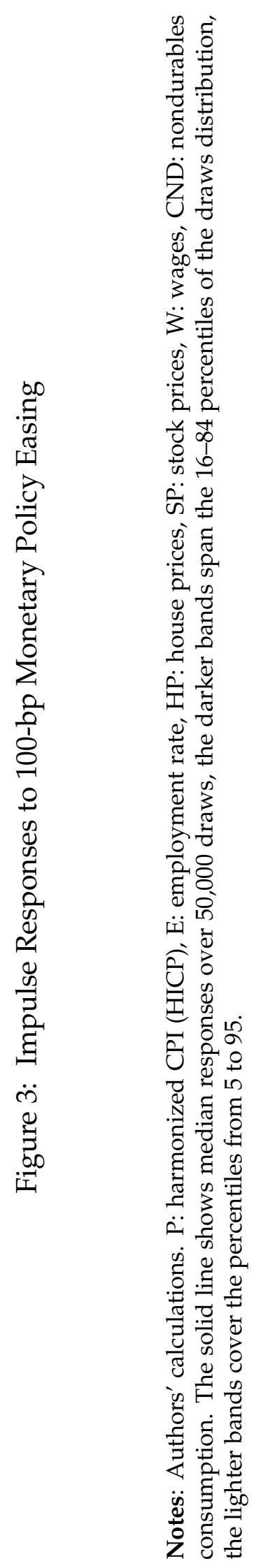


?, Figure 7 also find that the reaction of stock prices to monetary policy is strong, with a semi-elasticity to the interest rate around -20 for most countries. Nevertheless, we consider our estimate for stock prices to be on the upper bound of the range estimated in the literature.

In the rest of the paper we use the median responses of these variables after 1 year for our back on the envelope computation. To mitigate the measurement error which could result from the choice of a single horizon, we specifically focus on the average impulse response at horizons 3 to 5 . Table ?? summarizes the estimated impulse responses of employment, consumer prices, house prices and stock prices to a cut to the policy interest rate normalized to an initial size of -100 basis points.

We take into account that the policy rate returns towards the baseline after the initial shock. Thus, to compute the intertemporal substitution and the interest rate exposure components, we use its average response over the first year, which amounts to an average reduction of 80 basis points.

\subsection{Sensitivity of household eernings to aggregate earnings}

From the VAR, we compute the effect of the policy shock on aggregate labor earnings by combining the response of employment and wages in each country. Here we describe how we estimate the elasticity of household earnings to aggregate earnings for the three types of hand-to-mouth households.

We use the European Union Labour Force Survey (EU LFS). ${ }^{26}$ This dataset contains information about the employment status and demographics of a large sample of households-more than 100,000 individuals in each country (for ages 15-64).

Even though we are forced to use employment status as a proxy for earnings, because the latter are not reported in this dataset, we prefer this source to other surveys. The reason is that since 2005 the data include the week of the interview. This piece of information allows us to calculate employment rates at quarterly frequency and combine it with the quarterly time series for aggregate employment. ${ }^{27}$

We first impute the hand-to-mouth status to households in the LFS from the HFCS using a Mincer-style Probit regression of the hand-to-mouth indicator on persistent household characteristics: age, education, marital status, gender and sector of occupation. In the LFS, we use the fitted probabilities of belonging to each group to distribute households into the hand-to-mouth

\footnotetext{
${ }^{26}$ The EU Labour Force Survey is available at: https://ec.europa.eu/eurostat/web/microdata/ european-union-labour-force-survey; see the appendix in ? for a detailed description of the dataset.

${ }^{27}$ It is also well known that much of the variation of hours worked and total labor income over time is due to the extensive margin.
} 
groups and in doing so we respect, for each country, the shares of the total population in the three groups estimated from the HFCS.

We then estimate the employment 'incidence function' by the hand-to-mouth status as follows. Denote $e_{i t}(h)$ the employment status of reference person $i$ in quarter $t$ with hand-to-mouth status $h \in\{\mathrm{PHtM}, \mathrm{WHtM}, \mathrm{NHtM}\}$ (either 0 or 1 ) and $E_{t}$ the corresponding aggregate employment rate. The incidence regression has the form:

$$
e_{i t}(h)=\beta_{0}(h)+\beta_{1}(h) t+\gamma(h) E_{t}+\epsilon_{i t} .
$$

The estimated coefficients $\gamma(h)$ across the three groups, the empirical counterpart of the elasticities $\varepsilon_{y, Y}$ in the model, are shown in Figure ?? and summarized in Table ??. Overall, the elasticities tend to be large for the two hand-to-mouth groups, especially for the poor hand-to-mouth. The pattern is particularly pronounced for Spain and Italy, less so for France. In Germany, the poor hand-to-mouth have the highest elasticity, while the estimate of the elasticity of the wealth hand-to-mouth is lower than the non-hand-to-mouth. This positive correlation between MPC and exposure is a source of amplification of the shock compared to a representative agent model.

The pattern of the incidence function by HtM status that we uncover is broadly consistent with the results in ?, who combines estimated MPCs (instead of HtM status) by group of workers with estimated incidence of aggregate fluctuations on the same groups and finds a positive correlation. Other research has focused on the variation of household exposure across the permanent income distribution (not the hand-to-mouth status). Our estimates of elasticities tend to decline with permanent and actual income, a finding consistent with ?, ? for the US, and with ?, Chart $C$ for large euro area countries.

Our estimates of unequal incidence are unconditional. Separate work has investigated heterogeneous incidence conditional conditional on a monetary policy shock. ? estimate that expansionary monetary policy disproportionately stimulates incomes in the low tail of the distribution, predominantly via transitions from unemployment to employment. Similarly, ? find that employment rate in Germany in the bottom tail of the income distribution is particularly sensitive to monetary policy shocks.

\subsection{Measurement of households' exposures to interest rates, inflation and asset prices}

This section documents how balance sheets of households differ in their exposures to interest rates, inflation and assets prices. 
Figure 4: Net Interest Rate Exposures and Net Nominal Positions (Inflation Exposures) by Handto-Mouth Status, Mean, EUR Thousands

(a) Net Interest Rate Exposures

(b) Net Nominal Positions (Inflation Exposures)

Source: Eurosystem Household Finance and Consumption Survey, wave 2

Note: The left panel shows net interest rate exposures defined, following ?, as saving + maturing assets - maturing liabilities. Maturing assets are defined as: $25 \%$ of value of mutual funds, bonds, shares, managed accounts, money owed to households, other assets $+100 \%$ of deposits. Regarding maturing liabilities, we assume a duration of one year for adjustable-rate mortgages. We also add $100 \%$ of the outstanding balance of other noncollateralized debt. The flow of saving for non-hand-to-mouth households is calculated as the difference between their income and spending. Hand-to-mouth households are assumed not to save. See section ?? for detailed definition. The right panel shows net nominal positions defined, following ?, as their net nominal positions, consisting of nominal claims net of nominal liabilities and comprising items held both directly and indirectly, via investment funds (see section ?? for details).

\subsubsection{Net interest rate exposures}

Following our decomposition (and the insight of ?), we defined the net interest rate exposure as the difference between total maturing assets and liabilities plus the flow of saving (i.e. income minus total consumption). ${ }^{28}$

Net interest rate exposures differ substantially by household's hand-to-mouth status (Figure ??, left panel). At the euro area level, exposure is substantially negative for the wealthy hand-to-mouth households (around EUR -17,000) but only moderately so for the poor HtM, since unsecured credit is not prevalent in Europe. Interest rate exposure is positive for non-handto-mouth households (EUR 25,000). Therefore hand-to-mouth households will benefit from a reduction in interest rates through the direct channel. Non-hand-to-mouth households, in contrast, are negatively affected by the easing shock through a loss of financial income.

Net interest rate exposures vary considerably across the euro area countries. Flexible-rate mortgage debt is crucial to understand this heterogeneity. Around 80 percent of mortgages in Spain are adjustable-rate, while 90 percent of German mortgage contracts are fixed-rate. ${ }^{29}$ Correspondingly, Figure ?? documents that wealthy hand-to-mouth households in Spain display negative interest rate exposures over EUR -40,000, while exposure for the corresponding group in Germany is four times smaller. Moreover, German unconstrained households hold substantial positive exposures (around EUR 40,000), while the exposures of the same class of households in Spain are barely positive on average.

Collectively, these facts imply that households in Spain tend benefit more from the direct effect of an interest rate cut (via this channel) than those in Germany. France and Italy are in

\footnotetext{
${ }^{28}$ See Appendix ?? for detailed definitions. In short, maturing assets are defined as: $25 \%$ of value of mutual funds, bonds, shares, managed accounts, money owed to households, other assets $+100 \%$ of deposits. For maturing liabilities, we assume a duration of one year for adjustable-rate mortgages. We add $100 \%$ of the outstanding balance of other non collateralized debt. The exposure also includes the flow of saving calculated for non-hand-to-mouth households as the difference between their income and spending. Hand-to-mouth households are assumed not to save (they consume their income, possibly net of interests on debt if borrowers).

${ }^{29}$ While adjustable-rate mortgages enter maturing liabilities, fixed-rate mortgages do not.
} 
Figure 5: Housing Wealth and Stock Market Wealth by Hand-to-Mouth Status, Mean, EUR Thousands
(a) Housing Wealth
(b) Stock Market Wealth

Source: Eurosystem Household Finance and Consumption Survey, wave 2

Note: The left panel shows housing wealth consisting of real estate held as the household main residence and other real estate. The right panel shows stock market wealth owned in directly held stocks (da2105). Both means are calculated as unconditional, i.e. households with no housing or stock market wealth are included as holding EUR 0.

between these two extremes, but closer to Germany in this respect.

\subsubsection{Inflation exposures (net nominal positions)}

An established literature, at least since ?, has investigated how individual households are affected by surprise changes in the price level. Exposures of households to inflation risk are summarized by their net nominal positions, consisting of nominal claims net of nominal liabilities and comprising items held both directly and indirectly, via investment funds (see section ?? for details).

Figure ??, right panel, shows how net nominal positions vary by group. Similar to net interest rate exposures, they are negative for wealthy hand-to-mouth households, who tend to have more mortgage debt than financial assets, and are positive for non-hand-to-mouth households, who save in financial assets.

Across countries, the major discrepancy in inflation exposures arises between Germany and Spain. In the aggregate, German households hold positive nominal positions and Spanish ones negative positions. The reason is that savings of German non hand-to-mouth households are substantial (EUR 30,000), while those of Spanish non hand-to-mouth households are small. ${ }^{30}$ In contrast, inflation exposures of wealthy HtM households in both countries are more comparable. In fact, the median value of mortgage debt (conditional on holding a mortgage) is similar, around EUR 70,000, in both countries.

\subsubsection{Holdings of housing wealth and stock market wealth}

Figure ??, left panel, confirms the well-known fact that housing is the key wealth component of the wealthy hand-to-mouth households and non-hand-to-mouth households (between EUR $140,000-200,000$ on average). What is remarkable is that their gross housing wealth is nearly as large as that of the non hand-to-mouth ones.

\footnotetext{
${ }^{30}$ While the origin of this heterogeneity in portfolios is not strictly relevant for our exercise, we note that a possible determinant of differences in current inflation exposures across countries seems to be experienced past inflation, as documented by ? and ?.
} 
Figure 6: Effects of an initial 100-bp Monetary Policy Easing on Consumption, Euro Area

\begin{abstract}
Source: Eurosystem Household Finance and Consumption Survey, wave 2
Note: The figure shows a decomposition of the effects of an initial 100-basis-point shock to interest rates on consumption. The total consists of six parts. The direct effect of intertemporal substitution (IES) and the net interest rate exposure (NIE), and the indirect effect due to labor income, net nominal positions (Fisher), collateral / housing wealth and stock market wealth. Sizes of these effects vary depending on households' hand-to-mouth status.
\end{abstract}

Figure ??, right panel, shows that European households own little stock market wealth much less than US ones, for example. According to the HFCS, non hand-to-mouth households hold only EUR 7,000 of stock market wealth (the remaining households tend to hold almost no stocks at all). ${ }^{31}$

When we aggregate the total value of equities across households in the survey, we conclude that the HFCS covers about $70 \%$ of the total market value in each country (the coverage is especially low in Italy). We correct for this underreporting by boosting the stock wealth of the non-HtM households so that it matches the aggregate stock market wealth held by the household sector reported in aggregate data (Financial Accounts/Flow of Funds). Even with this correction, financial wealth remains an order of magnitude smaller than housing wealth in Europe. Thus, the effects of monetary policy via stock returns are bound to be minimal in the euro area.

We conclude by noting that we have made the implicit assumption that the value of business wealth does not respond to the monetary shock. In Appendix ?? we study the robustness of our results to the opposite extreme assumption that it responds as much as the stock market.

\title{
4 Results
}

In this section we illustrate the quantitative implications of our decompositions once we adopt the parameterization and the balance sheet structure described in the previous section. We start from our findings for the aggregate of the four countries (which we call the euro area) and then examine each country separately.

\subsection{Direct effects and indirect effects}

Figure ?? displays how the various individual channels we identified contribute to the changes in consumption expenditures for the three groups of households. We begin with the two direct

\footnotetext{
${ }^{31}$ The figure only includes directly held stocks. In our calculations we do not include stock market wealth held in pension funds. In Europe the bulk of pension insurance is public and the bulk of wealth in private pension insurance is held in bonds and other assets, other than stocks.
} 
effects. The figure shows that for non-hand-to-mouth households the intertemporal substitution channel (IES) accounts for the bulk of the stimulus and considerably affects aggregate consumption (almost 0.4 p.p. out of the total effect of 0.55 p.p.). The interest rate exposure (NIE) raises consumption of hand-to-mouth households via lower debt service (on adjustable-rate mortgages and on other debt), but it slightly reduces consumption of the remaining households who tend to hold positive net interest rate exposures/financial savings. ${ }^{32}$ In the aggregate, the NIE channel depresses consumption because the household sector is a net creditor (with respect to the other sectors), but its effect is small.

The figure also illustrates that the indirect effects account for by far the largest part of the consumption response for the two groups of hand-to-mouth households, $90 \%$ (or more) of the total effect. The indirect labor income effect is of overwhelming importance to the poor handto-mouth households. This channel and the housing wealth/collateral effect are the dominant ones for the wealthy hand-mouth households. The Fisher effect via the nominal exposures, turns out to be quantitatively moderate, except for the wealthy hand-to-mouth, mostly because of the limited response of inflation to monetary policy easing, but also because of the small size of net nominal positions. The stock market wealth effect is of little importance quantitatively. This is not surprising given the modest size of stock holdings shown in Figure ??.

Monetary policy shocks impact very differently the three hand-to-mouth groups, both qualitatively and quantitatively. Qualitatively, the indirect general equilibrium mechanisms are much more important for the hand-to-mouth households, while the intertemporal substitution effect is largest for the non-hand-to-mouth households. All in all, about 60 percent of the total increase in aggregate consumption is due to the indirect income and house price channels even at the aggregate level.

Quantitatively, hand-to-mouth households adjust their consumption by considerably more than the rest of the population after the shock. The initial 100 basis-point cut of interest rates results in an increase of consumption of 1.0 percent for the poor hand-to-mouth and of 1.8 percent of the wealthy hand-to-mouth, while consumption of the non-hand-to-mouth households rises by 0.5 percent. Given their disproportionate share in consumption (about $80 \%$ ), the non-handto-mouth households dominate the total consumption increase of 0.7 percent.

\subsection{Cross-country differences}

In comparing the results of our decomposition across the four countries, we focus our discussion on Germany and Spain, two 'polar' countries in terms of the homeownership rate, the prevalence

\footnotetext{
${ }^{32}$ Growing empirical evidence documents this channel is mostly driven by the passthrough of interest rates to disposable income via the debt service/cash flow channel. See ?, ?, ?, ?, ?, ?
} 


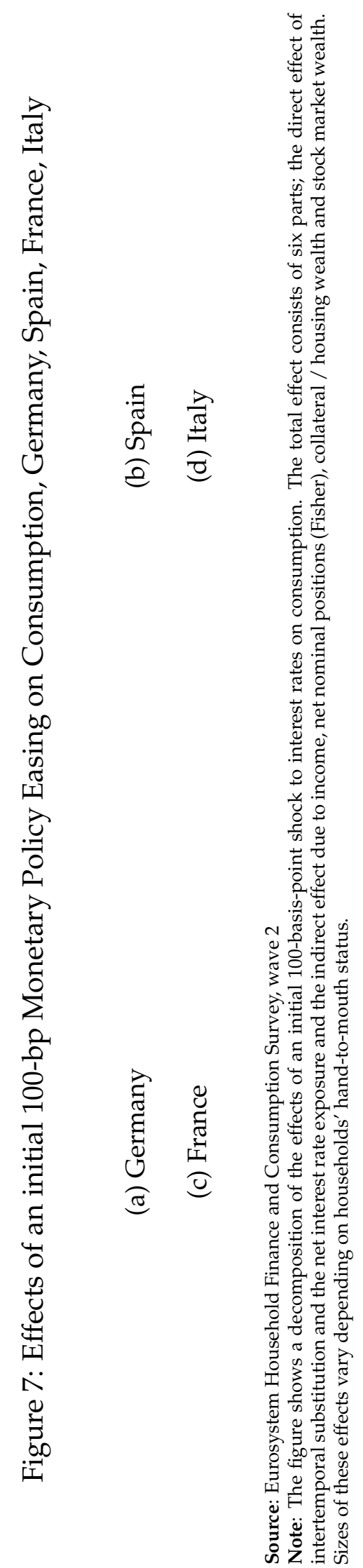


Figure 8: Effects on Consumption: Aggregate Responses vs Household Portfolios

\begin{abstract}
Source: Eurosystem Household Finance and Consumption Survey, wave 2
Note: The figure shows a decomposition of the effects of an initial 100-basis-point shock to interest rates on consumption. The baseline decomposition with country-specific VAR impulse responses is compared to the decomposition which imposes the same, euro-area-average impulse response across all countries.
\end{abstract}

of fixed- vs adjustable-rate mortgages and the volatility of the employment rate. Recall that gaps in homeownership translate into differences in the share of hand-to-mouth households: over 17 percent of Spanish households are wealthy hand-to-mouth compared to less than 12 percent in Germany. Figure ?? summarizes the results.

The intertemporal substitution channel is similar across countries. Instead, the markedly different portfolio composition of Spanish and German households implies that the direct interest rate exposure effect of a cut in the policy rate is large and positive in Spain, whereas it is slightly negative in Germany because households are net savers. The Fisher effects are of modest size for all households, except for wealthy hand-to-mouth households in Spain who benefit because of their sizable nominal debt holdings.

The indirect effects are largely shaped by differences in the aggregate impulse responses discussed in section ??. House prices and the employment rates respond much more strongly to monetary policy in Spain than in Germany. As a consequence, both the indirect labor income effects and the housing wealth/collateral effects in Spain considerably exceed their counterpart in Germany. The housing wealth effect in Spain is stronger both because of higher gross housing wealth (by roughly 40 percent, see Figure ??) and because house prices are much more sensitive to monetary policy (Table ??).

Adding up to obtain the composite effect, aggregate nondurable consumption responds very strongly in Spain (1.8 percent) and only modestly in Germany (0.4 percent).

Figure ?? shows that France and Italy are more similar to each other and the size of their consumption response arising from our calculations is between the two extremes of Spain and Germany. In Italy, like Spain, indirect equilibrium channels working through the labor and housing market dominate the decomposition. France is more similar to Germany because house prices and employment react little to monetary policy. ${ }^{33}$

Figure ?? analyzes how the cross-country differences in consumption responses is determined by the heterogeneity in the differential responsiveness of each economy to the common shock (from the VAR estimates) vs. the heterogeneity in household portfolios. The baseline response of

\footnotetext{
${ }^{33}$ Figure ?? shows the decomposition for the four countries and for the euro area all together with the same scale.
} 
Figure 9: Effects on Consumption: VAR vs HANK Decomposition

\begin{abstract}
Source: Eurosystem Household Finance and Consumption Survey, wave 2
Note: The figure compares the effect of an initial 100-basis-point shock to interest rates on consumption estimated using a structural VAR model to the HA decomposition. The HA model decomposition is broken down into two parts: the intertemporal substitution channel of the RA model and the remaining channels.
\end{abstract}

consumption (dark blue) is compared to a counterfactual where the VAR responses in all countries are set to be the same and equal to the average response (light blue). The fact that the latter responses are less dispersed implies that a significant share of these cross-country differences in consumption is driven by the heterogeneity in aggregate impulse responses.

\title{
4.3 Consumption response in HANK, RANK and VAR
}

Because our VAR includes nondurable consumption among its variables, we can investigate how the consumption responses estimated by the VAR compare to those implied by our model decomposition (Figure ??). This exercise can be thought of a validation of our HANK-based back-of-the-envelope calculations. ${ }^{34}$

The HA model performs well once the responses are aggregated to the euro area level, matching almost exactly the VAR estimate. In addition, it captures the cross-country differences between the high-response (Spain, Italy) and low-response (Germany, France) countries. However, it overestimates the consumption response in France and underestimates the one in Italy, relative to the VAR. ${ }^{35}$

The figure also decomposes the HANK consumption response into the part due to the IES channel (the RANK response) and the remaining parts. The IES response is stable across countries at around 0.25 percent. Therefore, heterogeneity always amplifies the response of the RANK models, in some countries very substantially. The main sources of amplification in the decomposition are the large MPC and the positive cross-sectional correlation between the MPCs and the increase in resources available to consume in the wake of a monetary easing. 
Figure 10: Effects on Consumption: The Top 10 Percent

\begin{abstract}
Source: Eurosystem Household Finance and Consumption Survey, wave 2
Note: The figure shows a decomposition of the effects of an initial 100-basis-point shock to interest rates on consumption. The total consists of six parts. The direct effect of intertemporal substitution (IES) and the net interest rate exposure (NIE), and the indirect effect due to labor income, net nominal positions (Fisher), housing wealth and stock market wealth. Sizes of these effects vary depending on households' hand-to-mouth status. The top 10 percent of households are defined as the $15 \%$ of richest households by net wealth among the non-hand-to-mouth (to account for the fact that the non-HtM households make up roughly $2 / 3$ of all households).
\end{abstract}

\title{
4.4 The top 10 percent
}

With our micro data it is easy to further decompose households into more groups. Given the growing interest in the widening gap between the richest and the rest of the population we can, for example, analyze how the consumption response to monetary policy shocks for the top 10 percent of the wealthiest households differs from that of the rest of the population. ${ }^{36}$

The top 10 percent of households differ from the rest of the unconstrained households because of their portfolios and their income incidence (see Appendix ?? for details). In terms of portfolios, the key discrepancy is in the amount of housing they own. While the rest of non-HtM households own about EUR 120,000 worth of housing in the euro area, the top 10 percent own over EUR 600,000 in housing. The two groups also differ in the holdings of stocks. The top 10 percent of households own about EUR 45,000 in equities, while the rest of the population owns virtually no stocks (Figure ??). As for the earnings incidence function, our estimates imply that the top 10 percent of households are somewhat more exposed to systematic fluctuations in income than the other non-HtM households (except for Spain), a result in line with ? and ? (Figure ??). ${ }^{37}$

The consumption response to monetary policy of the top 10 percent households is stronger than the response of the other non-HtM households, but still weaker than the response of HtM households (Figure ??). The key reason for this finding is that the top 10 percent gain substantially from increases in asset prices, especially stocks, even though they have a low MPCs. Their consumption responses are somewhat dampened by the losses via net interest rate exposures

\footnotetext{
${ }^{34}$ Another approach, which we did not follow here, would be to use the consumption responses of the VAR as target moments and calibrate the MPCs out of capital gains in each country (more likely to vary across countries than the MPC out of income because of the institutional differences in restrictions to equity extraction) so that the HANK decomposition matches the VAR responses exactly.

${ }^{35}$ At least in the case of France, it seems to be the VAR response that is too low (e.g., ? estimate that the consumption response in France lies between those of Germany and Italy).

${ }^{36}$ Because of sample size, we focus on the top $10 \%$. A smaller share would lead to very noisy outcomes.

${ }^{37}$ In all our calculations we assume that this group has the same MPCs as the other non-HtM households, i.e. an annual MPC out of income $5 \%$ and out of capital gains of $1 \%$.
} 
and the Fisher channel.

\subsection{Accounting for Business Wealth}

We conclude with a robustness exercise. Throughout the analysis, we abstracted from private business wealth. More precisely, we have assumed its value does not react to the shock. Let us now take the extreme opposite view that business wealth gets reevaluated as much as publicly traded stocks -recall that stocks react very strongly to an identified monetary easing in the VAR.

Figure ?? in Appendix ?? shows that this assumption has important consequences for the consumption response of the top 10 percent. This finding was expected in light of the well known fact that many among the richest households are entrepreneurs. Under this alternative assumption, their response more than doubles. What is more surprising is that also expenditures of the wealthy hand-to-mouth group react substantially more. The reason is that, for many households in this group, business equity is a large component of their illiquid wealth.

Overall, in this exercise the share of indirect effects of monetary policy exceeds $70 \%$, compared to $60 \%$ in the baseline.

\section{Conclusion}

In this paper we formulated a back of the envelope approach to quantify the various transmission mechanisms of monetary policy to household consumption in the four largest countries in the euro area. Our decomposition illustrates that these channels operate with different strength across the distribution of households, depending on households' marginal propensity to consume, portfolio composition, and exposure to aggregate fluctuations -all dimensions where heterogeneity is sizable.

We argued that a particularly helpful distinction, to summarize this large heterogeneity, is one that groups households in three classes: non hand-to-mouth, wealthy hand-to-mouth and poor hand-to-mouth based on their holdings of liquid and illiquid wealth.

By combining cross-country micro data on income and household portfolios with estimates from structural VARs on the impact of monetary policy on employment, inflation, and asset prices, we obtained all the ingredients we need to quantify the channels of transmission.

Our main finding is that the general equilibrium effects of an unexpected monetary easing on households' labor income, through an expansion in aggregate demand and an increment in house prices, are the principal determinants of the effect of monetary policy on aggregate consumption across countries. This finding suggests that households with low liquidity account 
for the lion share of the consumption response to monetary policy shocks. We also uncovered significant differences across countries: Germany displays the weakest response and Spain the strongest one to a common monetary shock.

Monitoring the composition of household balance sheets and the heterogeneous consequences of monetary policy across the distribution is therefore important to gain a better understanding of the monetary policy transmission mechanism.

While our analysis focuses on standard interest rate shocks, a similar approach can be taken to analyze the effects on unconventional monetary policy instruments, such as quantitative easing. For this set of measures, we would expect indirect general equilibrium effects to account for an even larger share of the total effect because the key channels of transmissions are a boost in asset prices and an expansion in aggregate demand. Who benefits more across the distribution will depend on the relative strength of these two forces (and whether house prices react more or less than stock prices).

Our methodology can also be applied to firms to assess the mechanisms through which monetary policy impacts aggregate investment. A quantitative literature which builds on traditional firm dynamics models is developing in parallel to that on heterogeneous household (??), but simple back of the envelope calculations of the type we did in this paper - that can give a preliminary idea of the magnitudes without the need for solving complex dynamic equilibrium models - are so far missing from this literature.

A limitation of the methodology implemented in this paper is that, because of the first-order approach taken in the decomposition and the linearity of the VAR, we cannot address nonlinearities and asymmetries between positive and negative shocks, nor we can examine the role of time-varying precautionary saving and hand-to-mouth status. The alternative approach followed in the HANK literature, which quantifies the transmission channels of monetary policy through richer calibrated or estimated DSGE models, is much more useful in this respect especially when globally solved nonlinearly. As discussed, ? and ? offer a compromise between these two approaches.

We think that the two methodologies should dialogue to best advance the HANK literature. The main lesson we learned here is that incorporating into richer HANK models endogenous mechanisms that lead to realistic fluctuations in individual earnings and asset prices is of firstorder importance. Progress in this direction is already being made. For example, ? integrates a job ladder and ? heterogeneity in risk aversion into HANK models. 


\section{A Measurement of variables}

\section{A.1 Definition of hand-to-mouth households}

This section classifies the three groups of households by their hand-to-mouth status. The variable names refer to wave 2 of the Household Finance and Consumption Survey (HFCS).

Following ?, a household is considered as 'hand-to-mouth' if:

- Net liquid wealth $\geq 0$ AND net liquid wealth $\leq$ biweekly (net) income OR

- Net liquid wealth $<0$ AND net liquid wealth $\leq$ biweekly (net) income - credit limit

A household is:

1. 'Poor hand-to-mouth' if it is hand-to-mouth AND net illiquid wealth $\leq 0$,

2. 'Wealthy hand-to-mouth' if it is hand-to-mouth AND net illiquid wealth $>0$,

3. Non-hand-to-mouth if it is not hand-to-mouth.

There are two (small) differences to ?. First, we classify all hand-to-mouth households with some housing assets (da1110 or da1120) as wealthy hand-to-mouth, including households 'under water' whose mortgage exceeds the value of the house. Second, we classify all hand-to-mouth households with some selfemployment business wealth (da1140) as wealthy hand-to-mouth.

The variables above are defined as follows:

- Net liquid wealth = liquid assets - liquid liabilities

- Liquid assets = sight and saving accounts (deposits), directly held mutual funds, bonds and stocks $=\mathrm{da} 2101+\mathrm{da} 2102+\mathrm{da} 2103+\mathrm{da} 2105$

- Liquid liabilities $=$ overdraft debt and credit card debt $=\mathrm{d} 11210+\mathrm{d} 11220$

- Net illiquid wealth = illiquid assets - illiquid liabilities

- Illiquid assets = illiquid real assets, value of household main residence and other properties and value of self-employment businesses $=$ da1110 + da1120 + da1140 + total $(p f 0710)+$ da2109

- Illiquid liabilities $=$ amount of non-collateralized loans for household main residence and other properties, mortgage debt

Credit limit is assumed at one month of income. 
Figure 11: Marginal Income Tax Rates

Source: OECD Tax Database, https://www. oecd.org/tax/tax-policy/tax-database/; Household Finance and Consumption Survey Note: The figure shows how (statutory) marginal tax rates depend on taxable household income.

\section{A.2 After-tax income}

After-tax income enters our calculation of saving (included as a part of net interest rates exposures) and of consumption-income ratios of non-hand-to-mouth households. Except for Italy after-tax income is not collected in the HFCS and needs to be approximated using marginal tax rates, as we describe below.

For France, Germany and Spain we approximate after-tax income by applying marginal tax rates available from the OECD on taxable income (variable di1100) $+2 / 3 \times$ self-employment income (di1200) and adding nontaxable income. For Italy after-tax income is available directly in the HFCS. Figure ?? shows the tax rates.

More specifically, for Germany we use the marginal tax rates as given by §32a of the 2014 EStG (German income tax law). For Spain, we use tax brackets and marginal tax rates based on the 2014 OECD data; the tables 'Central government personal income tax rates and thresholds' and 'Sub-central personal income tax rates-progressive systems', http://www.oecd.org/tax/tax-policy/tax-database.htm\#pit. For France, we use French-Property.com, https ://www.french-property .com/news/tax_france/income_ tax_bands_2014/. For Italy, the HFCS includes a variable on Income taxes and social contributions ( $\mathrm{hnG0710)} \mathrm{as} \mathrm{a} \mathrm{non-core} \mathrm{variable;} \mathrm{we} \mathrm{calculated} \mathrm{net} \mathrm{income} \mathrm{as} \mathrm{the} \mathrm{difference} \mathrm{between} \mathrm{gross} \mathrm{income} \mathrm{and}$ this variable.

Nontaxable income consists of transfers, income from pensions, rental income from real estate property, income from financial assets, income from private business other than self-employment, regular social transfers (except pensions), regular private transfers and income from other sources.

\section{A.3 Consumption-income ratios by hand-to-mouth status}

Both groups of hand-to-mouth households are assumed to consume their income. Nondurable consumption of non-hand-to-mouth households is calculated so that the aggregate saving in our economy matches the aggregate saving rates (given in Table ??).

In detail, denote aggregate consumption-income ratio $C / Y=\tilde{c}$ (the complement to the aggregate 
personal saving rate):

$$
\begin{aligned}
\tilde{c} & =\frac{C^{H}+C^{N H}}{Y}=\frac{Y^{H}+C^{N H}}{Y} \\
\tilde{c} \times Y & =Y^{H}+C^{N H} \\
C^{N H} & =\tilde{c} \times Y-\tilde{y}^{H} \times Y \\
\frac{C^{N H}}{Y^{N H}} & =\frac{\tilde{c}-\tilde{y}^{H}}{\tilde{y}^{N H}}
\end{aligned}
$$

where $\tilde{y}^{H}$ is the income share of HtM households $\left(\tilde{y}^{H}=Y^{H} / Y\right)$.

Assuming the share of nondurable on total consumption is the same for HtM and NHtM households, we get for nondurable consumption:

$$
\frac{C_{n d}^{N H}}{Y^{N H}}=\bar{c}_{n d} \times \frac{\tilde{c}-\tilde{y}^{H}}{\tilde{y}^{N H}},
$$

where $\bar{c}_{n d}$ is the aggregate share of nondurables consumption to total consumption, $\bar{c}_{n d}=C_{n d} / C$.

\section{A.4 Net interest rate exposure}

Net interest rate exposure is calculated following? (see also ? and ?).

- Interest rate exposure $=$ Income - Total consumption + Maturing assets - Maturing liabilities.

- Regarding the flow of saving (Income - Total consumption), we assume it is zero for hand-to-mouth households and its value for non-hand-to-mouth households is calculated so that it matches the aggregate saving rate (see ??).

- Maturing assets $=25 \%$ of (mutual funds, bonds, shares, managed accounts, money owed, other assets) $+100 \%$ of deposits.

- Maturing Liabilities = duration of 1 year for ARM $+100 \%$ Outstanding balance of non-mortgage $\operatorname{debt}^{38}$

- Outstanding balance of non-mortgage debt is defined as outstanding balance of credit line/overdraft, credit card debt and other non-mortgage loans.

\section{A.5 Inflation exposures (net nominal positions)}

Net nominal position is calculated following? and ?:

- Household net nominal position = Net financial position - Indirect nominal position

\footnotetext{
${ }^{38}$ The duration of 1 year for ARMs is a conservative estimate for the euro area, estimated following ?. For the US ? estimates the duration of three quarters.
} 
- Net financial position $=$ Financial assets - Total debt

- Indirect nominal position = Value of mutual funds (da2102) + Non-self-employment private business (da2104) + Publicly traded shares (da2105) 


\section{B Additional results on the top 10 percent households}

Figure 12: Housing Wealth and Stock Market Wealth for the Top 10 Percent, Mean, EUR Thousands
(a) Housing Wealth
(b) Stock Market Wealth

Source: Eurosystem Household Finance and Consumption Survey, wave 2

Note: The left panel shows housing wealth consisting of real estate held as the household main residence and other real estate. The right panel shows stock market wealth owned in directly held stocks (da2105). Both means are calculated as unconditional, i.e. households with no housing or stock market wealth are included as holding EUR 0. 


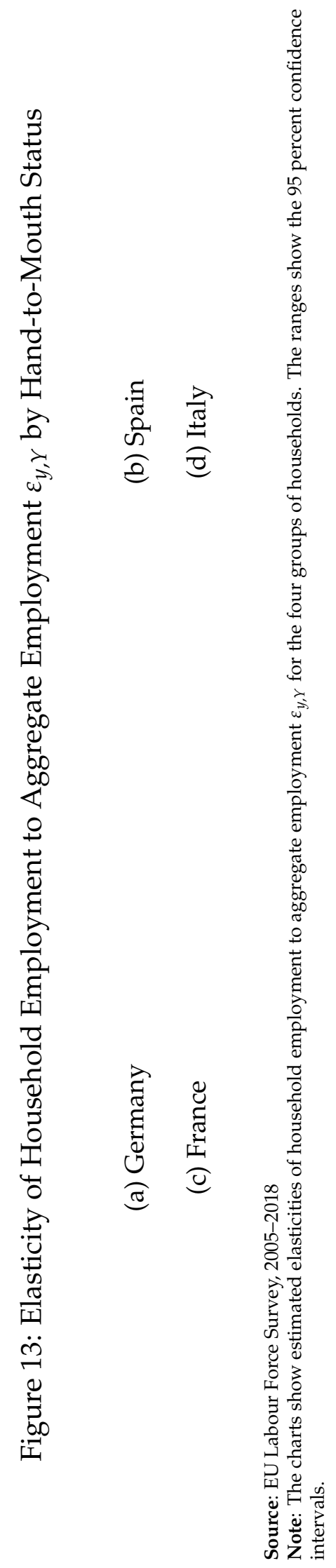




\section{Business wealth and other figures}

Figure 14: Effects on Consumption: Business Wealth Responds Proportionally to Stock Prices

Source: Eurosystem Household Finance and Consumption Survey, wave 2

Note: The figure shows a decomposition of the effects of an initial 100-basis-point shock to interest rates on consumption. The total consists of six parts. The direct effect of intertemporal substitution (IES) and the net interest rate exposure (NIE), and the indirect effect due to labor income, net nominal positions (Fisher), housing wealth and stock market wealth. Sizes of these effects vary depending on households' hand-to-mouth status. 


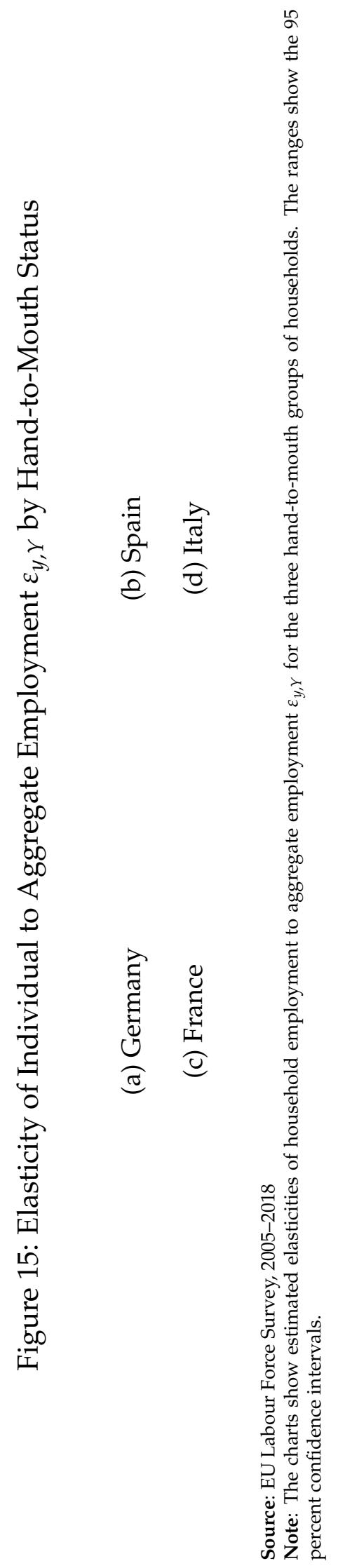




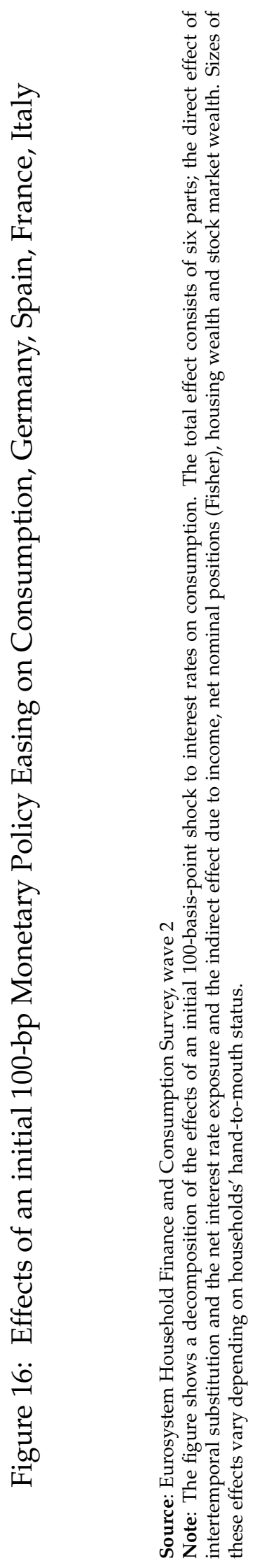

